\title{
TEMPO, ESCALA, TIEMPOS: EL RELATO DE LARGA DURACIÓN DE TAMARA KAMENSZAIN
}

\author{
Sandra Contreras \\ Instituto de Estudios Críticos en Humanidades, IECH \\ Universidad Nacional de Rosario \\ Consejo Nacional de Investigaciones Científicas y Técnicas, CONICET \\ Argentina \\ sandracontreras 123@gmail.com \\ Orcid: 0000-0003-469|-866।
}

Fecha de recepción: 21/06/2021| Fecha de aceptación: 24/08/202 I

\begin{abstract}
Resumen: La edición de La novela de la poesía (2012) ya hizo evidente dos cuestiones fundamentales en la escritura de Tamara Kamenszain: por un lado, una inscripción específica del pasaje poesía/novela/ensayo; por otro, el libro (la edición, el soporte, el objeto) como enlace. Más recientemente, El libro de Tamar (2018) y Libros chiquitos (2020) iluminan de un modo especial otros dos aspectos constitutivos del proceso: uno, la espiral temporal entre el programa de los años 70 y el presente de la escritura, que convierte la serie en una narrativa de larga duración; dos, el problema de los límites bajo la forma de la escala. En este trabajo propongo leer, en el cruce de El libro de Tamar y Libros chiquitos, tres escenas como inflexiones en un relato de larga duración con la prueba del tiempo y de los límites: el tempo de la prosa (la escritura del poema como ritmo del relato y la prosa como destilación de lo real del verso), las magnitudes del libro (el libro y la obra maestra de los años 70 , la poética de los libros chiquitos como una inflexión del sublime contemporáneo), el cruce entre la inscripción del presente y la creación de una comunidad.
\end{abstract}

Palabras clave: Tamara Kamenszain; Poesía argentina contemporánea; Narrativa argentina contemporánea; Ensayo argentino contemporáneo;Temporalidades.

\section{Tempo, Scale, Times: \\ The Long Duration Narrative of Tamara Kamenszain}

Abstract: The edition of La novela de la poesía (20I2) already made evident two fundamental issues in Tamara Kamenszain's writing: on the one hand, a specific inscription of the passage poetry/novel/essay; on the other, the book (the edition, the support, the object) as a link. More recently, El libro de Tamar (2018) and Libros chiquitos (2020) illuminate in a special way two other constitutive aspects of the process: one, the temporal spiral between the program of the 70s and the present of writing, which converts the series in a long duration narrative; two, the problem of limits in the form of scale. In this 
paper I propose to read, at the intersection of El libro de Tamar and Libros chiquitos, three scenes as inflections in a long duration story with the test of time and limits: the tempo of the prose (the writing of the poem as the rhythm of the narrative and the prose as the distillation of the real of the verse), the magnitudes of the book (the book and the masterpiece of the 70s, the poetics of the little books as a inflection of the contemporary sublime), the intersection between the inscription of the present and the creation of a community.

Keywords: Tamara Kamenszain; Contemporary Argentine poetry; Contemporary Argentine Narrative; Contemporary Argentine essay;Temporalities.

Tempo, escala, tempos: a narrativa de longa duraçáo de Tamara Kamenszain

Resumo: A edição de La novela de la poesía (2012) já evidenciava duas questões fundamentais na escrita de Tamara Kamenszain: de um lado, uma inscrição específica do passagem poesia/romance/ensaio; de outro, o livro (a edição, o suporte, o objeto) como elo. Mais recentemente, El libro de Tamar (2018) e Libros chiquitos (2020) iluminam de maneira especial dois outros aspectos constitutivos do processo: um, a espiral temporal entre o programa dos anos 70 e o presente da escrita, que converte a série em uma narrativa de longa duração; dois, o problema dos limites na forma de escala. Neste artigo, proponho-me a ler, no cruzamento de El libro de Tamar e Libros chiquitos, três cenas como inflexões em uma narrativa de longa duração com o teste do tempo e dos limites: o tempo da prosa (a escrita do poema como ritmo da narrativa e da prosa como destilação do real do verso), as magnitudes do livro (o livro e a obra-prima dos anos 70, a poética dos pequenos livros como inflexão do sublime contemporâneo), o cruzamento entre a inscrição do presente e a criação de uma comunidade.

Palavras chaves: Tamara Kamenszain; Poesia argentina contemporânea; Narrativa argentina contemporânea; Esaio argentino contemporáneo; Temporalidades.

S i la obsolescencia y la corta duración definen la experiencia del tiempo en el mundo contemporáneo, donde lo nuevo es "el abandono radical de la pretensión de que el tiempo se acople a cualquier proyecto a largo plazo" (Crary 36), narrativas monumentales como los seis tomos de Karl Ove Knausgård o proyectos desmesurados como los de Rafael Spregelburd en el teatro o los de Mariano Llinás en el cine, conllevan, en las dos últimas décadas, el recordatorio de ese insumo insustituible que es el tiempo en el encuentro de un lector o de un espectador con el relato de una historia. Más allá del modo divergente en que se vinculan con el mercado, obras como $M i$ lucha (2009-2011), La terquedad (2008) o La flor (2018), pueden leerse como economías ficcionales de la extensión que, en el contexto del nuevo capitalismo que alteró las nociones de ocio y de trabajo y que afectó sensiblemente las formas de atención, objetivan, a gran escala, el volumen de tiempo que demanda su consumo y el de trabajo invertido en su producción, además de hacer visible, en general, la apuesta por lo grande, en el sentido de ser "la máxima expresión de algo". Títulos y despliegues compositivos como los de El pasado (2003) de Alan 
Pauls, El espectáculo del tiempo (2015) de Juan José Becerra, o El absoluto (2016) de Daniel Guebel, inscriben con diversa intensidad en la narrativa argentina contemporánea señales de esa ambición.

El reciente Libros chiquitos (2020), que Tamara Kamenszain escribió para integrar una colección de escritorxs e intelectualxs que recorren sus historias de lecturas, va claramente en la dirección contraria. El título también objetiva la obra y su tamaño, pero el valor de la magnitud no solo invierte, sino que transforma su sentido. Ni opción por la forma breve (pueden ser "chiquitos" volúmenes de 500 páginas como La novela luminosa de Mario Levrero o de extensión promedio como El nervio óptico de María Gainza), ni apuesta por lo menor en una supuesta disputa sobre el canon (en la serie puede haber libros de Giorgio Agamben, de Nicanor Parra o de Fabián Casas), lo "chiquito" de Kamenszain es índice del grado en que ciertos libros, que pueden ser interminables como Museo de la novela de la eterna, se sustraen en su devenir a la extensión ("se achican -dice- justamente cuando parece que van a crecer") (Libros chiquitos 12), e índice, por lo tanto, del grado en que esa sustracción a lo grande, que siempre paraliza, impulsa a la lectora a escribir. Lo "chiquito", entonces, como un modo de leer que activa el deseo de escribir. El "cálculo" de palabras, sin embargo, está en el umbral del libro, solo que irónico y aligerado. Porque si la lectura del librito de 45 páginas que su amiga Paloma Vidal se propuso escribir y terminar, a razón de 55 palabras por minuto, en las dos horas de un viaje en avión, le sirve para sortear la inquietud ante el mínimo y máximo de palabras del contrato editorial que la enfrenta a uno de sus "flancos vulnerables", la escasa extensión de lo que escribe (10), lo que Kamenszain ve y subraya en Ensaio do voo (2017) es sobre todo el ejercicio físico de una escritora que, "si no par[a], si no desaceler[a], si no levant[a] la cabeza", puede llegar a 6600 palabras antes de bajar (9-10): es esa práctica liviana, diferente de los esfuerzos maratónicos por llegar a la última página como un trofeo, lo que a la lectora "motiva" (10) o, como dirá más adelante, le "despiertan ganas" (47) de escribir. Lo "chiquito", entonces, como una forma de investir la pulsión de la escritura, esto es, una economía que se mide en cuantos de energía, y un útil para la práctica. $Y$ es en el sentido del valor de uso de una caja de herramientas, en lugar del valor de cambio de la biblioteca, que Libros chiquitos monta una "antología de lecturas de trabajo", inútiles para adquirir erudición, pero "absolutamente útiles para ponerse a escribir" (12).

Por eso, dice Kamenszain, la poesía, en cuya lectura siempre vive "levantando la cabeza para anotar algo [suyo]" es el "primer apto" para integrar la serie: porque "a golpe de cortes impide -dice-, desde la frase misma, cualquier tentativa de extensión" (12). La novela, sin embargo, esa forma que se alarga frente al verso y que por definición lleva implícita la continuación y la duración, se inscribe también, como sabemos, crucialmente, en su literatura. En este sentido, la edición de La novela de la poesía, el libro que en 2012 reúne sus poemarios, desde De este lado del Mediterráneo (1973) hasta el inédito que cierra y da título 
al volumen, hizo evidente dos cuestiones clave. Por un lado, designa esa capacidad que para Kamenszain tiene la poesía para escribir su propia novela y que, en la precisa fórmula de Enrique Foffani, consiste en "escribir la novela que la poesía contiene" (8). Por otro, hizo palpable el libro (la edición, el soporte, el objeto) como enlace: como si ese notable enlace entre libros contiguos -entre temas, leitmotivs, figuras, procedimientos, gestos- que funciona como principio constructivo de la obra (Foffani 12) se objetivara ahora, no en la espiral de la reescritura sino en el libro mismo como huella material de ese espiralado.

Más recientemente, El libro de Tamar (2018) introduce una variante en esa larga exploración del pasaje verso/prosa, novela/poesía. No solo no se trata de la prosa poética que ya había quedado atrás en su libro de 2012 ("La prosa poética ya fue / la novela lírica con evocaciones de infancia / ya fue ya fue ya fue") (La novela de la poesía 385) sino que tampoco se trata de postular la novela, con su nombre, como lo hace el último verso de El eco de mi madre ("... a lo mejor/ ...quién te dice.../ mañana empiezo una novela.”) (368), ni de inscribir su hipótesis en el futuro como lo hacen los últimos versos de La novela de la poesía ("para que mañana si me queda tiempo / yo te pueda pasar en claro mi cuaderno / escribirte por ejemplo un ensayo titulado / LA NOVELA DE LA POESIA") (393). Se trata ahora, en cambio, de la poeta ante el impulso de escribir en prosa para develar, en forma póstuma, la historia de amor contenida en el poema que el exmarido, quince años atrás y poco tiempo después de la separación de la pareja, le escribió y le deslizó por debajo de la puerta, como un mensaje. El poema, que incluye cinco versos ("Arma trama, Ama: / jara mar! / Ata rama / mata rata / (mata tara)."), el dibujo de una rama entre el tercero y el cuatro, más una dedicatoria ("A Marta Marat") y un lugar y fecha como firma ("Ramat", 2/7/00), consiste en una serie de anagramas del nombre con el que lo titula, "Tamar", que "es y no es" el de la escritora. Cuando la hoja reaparece por casualidad en medio de papeles viejos, diez años después de la muerte de su autor, solo entonces el poema (casi un haiku, dice Kamenszain) del que fue novelista interpela a la poeta e impulsa a escribir ${ }^{1}$. Se impone entonces, y es la escena inicial del libro, la elección del medio: así como el novelista depuso -dice Kamenszain- sus condiciones de narrador y escribió en verso, así la poeta se separará del medio que le es propio y que domina ("deponer" es "apartar algo de sî") porque, intuye, solo en prosa podrá hacer entendible lo que él versificó y lo que ella en cambio, en esta ocasión, no podrá expresar en verso. Es sin duda un primer acto de amor en la escritura -hablar la lengua del otro-, pero para la poeta es también un modo de medirse con sus aptitudes: el ejercicio es nuevo ("estos pasos de prosa que estoy empezando a ensayar", dice Kamenszain) ( $E l$

1 En relación con La preparación de la novela, que, "enorme en páginas, pero chiquito en intención", es su "antologable por excelencia" (Libros chiquitos 69), Kamenszain subraya una y otra vez la función clave del haiku para Roland Barthes: como procedimiento poético que está en la base de la preparación de cualquier novela (12) y como atajo para acortar camino entre crítica, poesía y novela (69). 
libro de Tamar 34), implica un desafío (escribir en prosa implica "narrar" y la escritora advierte al comienzo que sabe "poco y nada" de ese oficio) (14), y es también una nueva forma de practicar con los límites de la extensión. En efecto, mecanografiado en una hoja $\mathrm{A} 4$, el poema iba además precedido de una nota manuscrita en la que "él" -el exmarido, que en el relato será luego el padre de sus hijos, y finalmente el escritor, el novelista, Héctor Libertella, que murió en 2006- le deja dicho que "emer[gía] de un sueño con la máxima cantidad de anagramas y combinaciones de [s] u nombre" e interpela a la poeta, a través de la pregunta, a desplegar los tantos significados contenidos allí: "¿Tanta cantidad de bolsones pueden esconder cinco letras?” (11). Kamenszain reproduce la hoja con el poema y la nota en la primera página; y nuevamente, en el umbral de libro queda implícita la cantidad.

“'Los límites del poema-libro' llamé cuando era joven / a la posibilidad de escribir un libro que todo entero fuera de poemas / y todo entero sin embargo / contara algo. / No era nada original no era ninguna genialidad / pero ahora me parece que solo ahora me toca probar esos límites." Estos versos, que abren el capítulo II de El libro de los divanes (14) remiten a un texto publicado en la revista Dispositio en 1975, una suerte de ensayo-manifiesto muy en el estilo textualista y programático de los años 70 . Kamenszain postulaba allí un poema proyectado no en un libro-de-poemas como mera reunión accidental y cuantitativa sino en un poema-libro cuya extensión, macedoniana, aspirara a la narración, y cuya expansión, arquitectónica y mallarmeana, conquistara el espacio, ilimitadamente, contra todo límite. Como se ve, la extensión y la expansión son intereses de larga duración en la escritura de Kamenszain, aunque solo "ahora", dice la que habla en el poema de 2014, probará esos límites.

El libro de los divanes, el libro del "sueño del fin del análisis" (Moreno 2021), constituye sin dudas un gozne en la literatura de Kamenszain. Imaginado como equivalente del "pase" psicoanalítico, el libro relee, desde su primera línea, toda la obra. Solo que, como muy bien observa Alejandra Laera, es porque La novela de la poesía significó ya una retemporalización de la obra reunida en 2012 y con ella "una relectura de la poesía en clave de vida y de la vida en clave poética", que en El libro de los divanes puede hablarse de todos los temas "haciendo convivir todas las temporalidades a la vez" "“la infancia, el pasado, lxs amigxs, los libros, las lecturas, lxs hijxs, la muerte de los padres, la política, los sueños, facebook, lxs analistas, el análisis") y queda habilitado el "pase" como salida de sí hacia el imaginado cierre del libro mismo como "final" (Laera 2). Creo que hay aún otro indicio de ese gozne y es la precisión con que el pasaje novela/realidad que anticipa el epígrafe de José María Heredia (“¡Oh! ¿Cuándo acabará la novela de mi vida / para que empiece su realidad?") acota un nuevo sentido para la idea de "novela" que, ahora, vira al pasado, al "mito de origen", a la evocación, ante una escritura que "hoy" pugna por "consignar el presente" y "disponerse" a la realidad. Me interesa subrayar que ese pasaje, que en el cierre del libro la que habla intuye como un "vislumbrar un final ponerlo en presente 
/ no evocarlo no novelarlo pero sí / transformarlo en una realidad" (71), parece venir ahora con la prueba de los límites: los del poema-libro pero también los de la realidad ${ }^{2}$.

Parto entonces de esos versos de El libro de los divanes, y del montaje allí postulado entre el presente de la escritura y el programa de los años 70, para leer, en el cruce de El libro de Tamar y Libros chiquitos, tres escenas como inflexiones en un relato de larga duración con la prueba del tiempo y de los límites: el tempo de la prosa, las magnitudes del libro, el presente del "ahora” y la comunidad.

\section{Tempo}

El "paso de prosa", aquello que tiene lugar cuando el verso, en el corte que lo define, se siente irresistiblemente atraído a encabalgarse sobre el siguiente, para asir lo que arrojó fuera de sí, es, dice Giorgio Agamben, "un arrojarse de cabeza al abismo del sentido" (25). El libro de Tamar se escribe en este vértigo, como si escribir en prosa no implicara simplemente desplegar la novela contenida en el poema sino caminar en una suerte de borde filoso, siempre con el vértigo de "caer[s]e al precipicio" (34). Así parece percibirlo la poeta cuando advierte que, ahora que está narrando, no es del todo dueña ("Ama" es el título del fragmento) de sus palabras. Dice: "no puedo despacharme con lo que se me ocurra porque las propias palabras de mi exmarido me van marcando el límite, que es como decir que le van poniendo el título a cada uno de estos fragmentos" (34). En El libro de Tamar escribir en prosa es así, en principio, narrar dentro de los contornos del poema, no porque sus ocho líneas (título, dedicatoria, versos, dibujo, firma) "dicten" una forma o un orden (de hecho el relato salta de una a otra para titular los fragmentos) sino porque ellas actúan como el hilo de la trama para una poeta que se desorienta en el flujo ininterrumpido de la prosa ("a cada rato tengo que detenerme para no perder el hilo") (34), pero también, y sobre todo, ante la "proliferación de bolsones semánticos" (49) que, a través del relato, extrae de los versos y consigna como exceso: "Entonces, yo me pregunto en nuestro caso / si cinco letras pueden decirte a vos lo que me dejaron / de decir a mí o al revés si a lo mejor yo / les hago decir ahora más de lo que pueden / para que nos unan a la fuerza / como quien encuaderna en uno dos libros." (86). Como si entre las insinuaciones de desvío o de desborde de la prosa, las líneas del poema volvieran a poner el corte (como versos) y marcaran los puntos de retorno en la periódica recapitulación.

El movimiento inverso también se verifica. En efecto, sea para resolver dudas que la asaltan en la "enésima relectura" del poema de su ex (49-50), o para salir de la confusión y del tedio que le provoca, por ejemplo, intentar desentrańar el sujeto elidido del poema (35-36), Kamenszain prueba a escribir ella misma un

2 "Hoy soy yo la que le pregunta a Facebook / por los límites de la realidad. / ¿Está mal hacer un asado en la ESMA?" (47). 
poema, es decir, a volver al terreno que le pertenece y que domina, para decir por fin en verso el enlace o la conclusión: "Los anagramas de mi exmarido / -me doy cuenta recién ahora- / son en realidad rimas tristes / palabras que se van atando / unas sobre el final de las otras / para decir por fin en verso / algo que vuelva a juntarnos a mí, a ti, / a él, a ella / en un nosotros tardío" (37). Lo mismo ocurre en el final del libro: como si no hubiera otro modo de poner fin a la historia de amor contenida en el poema ("si se tratara de una película, / yo lo resumiría con la palabra FIN") (88) si no es con un poema que ahora prueba a escribir a cuatro manos con La historia de nuestras vidas de Mark Strand. A diferencia de los poemas propios anteriores que cita y relee a lo largo del relato, los que escribe en medio del paso de prosa son precisamente los que le sirven para salir del paso o para poner fin ${ }^{3}$.

Pero las líneas de Libertella no son los únicos límites que le van marcando el paso a la prosa de Kamenszain. Porque si la escritora no puede decir lo que se le ocurra sobre su ex es también porque sus hijos, sea porque escribieron o porque hablaron, es decir, porque "ya saben y [l]e enseñan", ya dieron testimonio sobre él (34). Con el ritmo marcado por la palabra-testimonio de los hijos, el paso de prosa de El libro de Tamar consiste también, entonces, en una destilación de lo real: tanto de la realidad que ahora lee "bajo el maquillaje anagramático" del poema (una dedicatoria "por fin real", un pedido de ayuda real, el dibujo infantil de la rama como constancia de realidad) como de las palabras y voces reales que solo ahora puede escuchar entre los versos propios de Vida de living (1991), El ghetto (2003) y Tango Bar (1998) .

El poema, entonces, la escritura del poema, marca el ritmo del relato en $E l$ libro de Tamar: dosifica sus materiales, provee sus retornos. A la vez, la prosa como destilación de lo real del verso instala un tempo entre los versos-títulos, que escanden el relato con sus "golpes de realidad", y la continuación, como enlace propio de la novela 5 . Y ese tempo es preciso para poner en marcha el relato como forma de volver a leer y de volver a escuchar.

3 ¿Dónde poner el corte?, ¿cómo poner fin?, es para Kamensain el problema propio del pasaje entre el verso y la prosa, y uno de los grandes temas de El libro de los divanes, que termina así: "y sé también que en algún momento / debería cerrar este libro y tampoco sé cómo / salvo que el final / caiga como una fruta madura / y pegue en la cabeza de alguien que por fin / pase por aquí" (72).

4 Otra forma de leer el pasaje entre poema y paso de prosa es la que propuso Mario Cámara en la presentación del libro: un "impresionante trabajo de traducción" al cabo del cual los versos herméticos parecen "hablar claro", que consiste en aproximarse al poema a través de la retórica cortesana en torno al nombre secreto de la dama. En El libro de Tamar, dice Cámara, "hablar claro entonces no significa salir de la literatura, sino leerla de otra manera. Transfigurado por la clave amorosa, el poema comienza hablar con una lengua nueva" (s/d).

5 La idea del estribillo como "golpe realidad", que, rítmicamente, libera de "lo que sobra" y recuerda "lo que hay", está desarrollada en el capítulo "Leer estribillos" de Libros chiquitos (1923). En El libro de Tamar, la misma figura le sirve a Kamenszain para leer los títulos de los capítulos de Black out como la forma en que María Moreno dosifica, rítmicamente, "todo lo que de real tiene para contarnos" (48-49). 


\section{El libro}

El libro de Tamar, que habla por la boca del testimonio, puede ser leído también como la desclasificación de un archivo. Hace público un secreto: la "lengua indescifrable" que unía indisolublemente a la pareja como una contraseña y que al mismo tiempo la separó ${ }^{6}$. Y publica un inédito: no solo el poema de Libertella, sino también la reproducción de la hoja blanca y ajada en la que, dice Kamenszain, ahora que viró al sepia, lo mejor de la prosa libertelliana brilla materialmente en la letra manuscrita (63-64). En los versos finales del poema que escribe a cuatro manos con Mark Strand, la que habla dice que "guarda" la hoja otra vez, ahora en un folder transparente, y en las fotos del celular (87-88), como si fuera preciso consignarlo otra vez, ahora en la nube del archivo digital, para cerrar el libro y la historia.

Me interesa subrayar aquí el acto mismo de la publicación, un episodio central en la historia de la pareja, que ilumina a su vez la pasión por el libro, también central en la historia de la "generación" -la generación en la que Kamenszain dice una y otra vez haber "nacido" y en la que "militó", a favor del "textualismo duro y puro" (18), el matrimonio literario ${ }^{7}$. En efecto, en El libro de Tamar, todo él un enlace entre una hoja y un libro (este mismo que se escribe, pero también el libro que lee la pareja del poema de Mark Strand y con el que Kamenszain identifica el suyo), se superponen varios. Y es que al titularlo "el libro" y no "el poema” Kamenszain no solo vuelve a inscribir allí el libro de los judíos, sino que, sobre todo, devuelve el poema a uno de los medios favoritos de su autor: destellan ahí el libro-objeto que Libertella fabricó - diseñó, armó, forró- como ejemplar único de su primera novela (68), y también el libro material -el formato, la tapa, los 3000 ejemplares cosidos a mano- que sońó para el primer volumen de ensayos de Tamara Kamenszain que él mismo le publicó en México, como editor (43-44).

Pero en el de Libertella resuena también el libro publicado de los años 70. Quiero decir, el libro que la biografía de Ricardo Strafacce (2008) pone en el centro de la vida de Osvaldo Lamborghini como consumación de una literatura indisociable de la "apoteosis de publicar" y, sobre todo, como objeto ligado primero al deseo, enseguida al fantasma y finalmente a la carga abrumadora de la obra maestra como destino. Quiero decir, también, la atracción por el artista que escribe una obra maestra, tal vez "cifrada y escondida entre los libros", que atraviesa Los diarios de Emilio Renzi que Ricardo Piglia publicó entre 2015 y 2017,

6 El secreto, dice Jacques Derrida en Mal de archivo, es lo que divide y separa, y va así en contra del principio de consignación del archivo, cuya función es reunir (11).

7 "Nací en una generación. / La muerte y la vida estaban / en un cuaderno a rayas" son los versos "emblemáticos" de Osvaldo Lamborghini con los que Kamenszain se inscribe, en La novela de la poesía, en la generación de los años 70 (nucleada en torno de las ideas de escritura y texto, de Tel Quel, del posestructuralismo, la teoría, el psicoanálisis, la política) y que en El libro de Tamar emerge más claramente como el ghetto del "formalismo duro y puro". 
y que, notoriamente, hace serie con su "apuesta a todo o nada" por ser un "gran escritor" y su consiguiente, y periódico, miedo al fracaso ${ }^{8}$. El libro, entonces, y la obra maestra como cifras de una concepción agónica de la literatura, de la que también da cuenta la más joven María Moreno cuando en Black out (2016) atestigua la apuesta por la posteridad de Norberto Soares en sus cuadernos marca Gloria $(143,150,156)$ o el temor de Miguel Briante ante lo mismo que buscaba: "fama, gloria, reconocimiento" (197). Una concepción y también una escena que quedará fotografiada en La arquitectura del fantasma. Una autobiografía (2006), cuando Libertella entrevea, poco antes de morir, que pronto, a sus 65 años, los jóvenes sobrevivientes del "Salón Literario" de los 70 (Arturo Carrera, César Aira, Josefina Ludmer, también Tamara Kamenszain, él mismo) "volver[í] an a colgar aquel cartel que alucinaba a todos en la esquina de Paraguay y Florida: SOMOS GENIALES" (59)'. El libro de Tamar y Libros chiquitos, propongo, entran también a esta constelación de relatos, solo que para abrir una tangente, porque, claramente, tanto la liberación del "formalismo puro y duro de los 70 " del que da testimonio la poeta-narradora en el primero, como la pulsión de lo chiquito que descubre en el segundo, pueden medirse en relación, y por contraste, con esa ambición.

Por esto no solo la "liberación" sino también el "alivio" es una imagen recurrente, en estos dos relatos últimos de Kamenszain. Pienso en la liberación tanto del "ojo crítico" de Libertella como de sus propias "ataduras retóricas", que está en el nudo de la historia de la pareja y en la de su escritura (El libro de Tamar 26). Pero pienso también en la sensación de alivio que le produjeron Manifiesto por la filosofía de Alain Badiou o Estancias de Agamben, cuando vio que la alejaban de los "grandes temas" (Libros chiquitos 51); o en la suspensión "entre que le cuenten algo y de golpe dejen de contárselo" con la que el estribillo, que la atrapa en el ritmo de la poesía de Enrique Molina o Néstor Perlongher, le produce "el placer de anticiparse a dejar de leer" (Libros chiquitos 14, 22). Y me pregunto si ese juego de ritmos que lo chiquito entabla entre narrar y suspender, entre interrupción y retorno, entre grandeza y alivio, no podría leerse como una inflexión contemporánea de lo sublime. El "deleite" (alivio) que se encuentra en la suspensión de lo que amenaza al sujeto (la amenaza de privación y de muerte

8 El peso de la "obra maestra" como destino para el escritor "genial", unida al valor del libro publicado, es una de las hipótesis fuertes de Strafacce en Osvaldo Lamborghini. Una biografia; la desarrolla en varios momentos del libro $(201,207,209,222-223,358-359,453-455)$ y la apoya en cartas del escritor ("El texto, sí, pero en el libro" 423). También son varios los pasajes de los Diarios de Piglia que remiten tanto al valor de la obra maestra, la obra monumental, la gran novela, o, por ejemplo, el hecho de estar escribiendo, tal vez sin saberlo, "la mejor literatura de su tiempo" (Años de formación 49, 52, 66; Los años felices 62,74, 344), como a la apuesta a todo o nada por la "literatura" como una "carrera" en la que se consignan fracasos y triunfos (Años de formación 177, 212; Los años felices 20, 173, 178, 229; Un día en la vida 59, 88).

9 En las páginas finales de Black out, María Moreno cuenta que cuando "los muchachos", conscientes de su privilegio de "testigo" (en las rondas de escritorxs y periodistas en los bares de los años 60 y 70), le sugirieron que escriba sus memorias, Germán García propuso un título maligno: "Qué pequeños eran los grandes del 70" (397). 
que producen los objetos grandes, muy grandes o muy poderosos: la oscuridad, el silencio, la nada) es, como se sabe, el signo mismo de lo sublime. Al alejar o suspender esa amenaza -así explica Jean-Francois Lyotard el tratado de Edmund Burke-, el arte procura no una satisfacción sino el placer del alivio: entonces el alma se entrega a una agitación entre la Vida y la Muerte, y esa agitación es su salud (Lyotard 104). El de Kamenszain en Libros chiquitos es un alivio de una intensidad diferente. Es el alivio de "lo que sobra", que llega con el recordatorio de "lo que hay" (20). Es un alivio "inofensivo", precisamente porque la ambición de lo grande nunca estuvo en juego. Es un alivio alegre, un atajo, una treta. Podríamos cotejarlo, para calibrar su tono e intensidad, con la inflexión desencantada de lo sublime que atraviesa las 3500 páginas de Knausgård, donde la lucha del escritor por confrontarse con "lo grande" (sea la muerte, sea una larga historia larga contada en una gran novela por entregas) reclama, antiproustiano y romántico a la vez, "la añoranza de sentido" (552). Kamenszain no inscribe ninguna lucha en su título; pero igualmente objetiva, y casi diría que literaliza, el tamaño de la obra: un indicio tal vez de que, como dice Silvia Schwarzbök, el tamaño hoy se vuelve relevante para la estética, justamente porque lo sublime ha perdido vigencia (55). En la economía de la extensión de Kamenszain, el gran alivio de lo chiquito funciona como transformación alegre de lo sublime: lo portan las "novelitas", no las de César Aira, sino las de "las chicas", que "llevan tatuadas las tretas de las débiles" y ensayan formas breves "que pueden resolverse en 6600 palabras con belleza y, por qué no, con felicidad." $(90-91)^{10}$.

\section{Tiempo}

La "obra maestra" del 70 suele ir asociada a cierta proyección hacia el futuro, en la forma de la poética del manuscrito póstumo, o en la forma de cierta ansiedad por la posteridad, por la inscripción en la historia de la literatura (argentina). ${ }^{11}$ En otra dirección, la temporalidad póstuma en la que Kamenszain dice encontrar la necesidad de abrir el inédito ("Ahora, pasados tantos años y con la mediación de su muerte, una temporalidad póstuma me encuentra en la necesidad de digitar la

10 Con el término "novelitas", Kamenszain se refiere en Libros chiquitos a las "novelitas de hoy" que, escritas en primera persona y en presente, y desde un "punto de vista casi banal", parecen "anotar" situaciones, desestabilizando su condición de ficción (79-80). Son las novelas de "una nueva generación de arriesgadas", que saltan entre los géneros, aunque sin los objetivos programáticos de la vanguardia: "Hoy -dice- hay chicas que practican sin culpa este ejercicio" (80), como Verónica Gerber en Conjunto vacio, o María Gainza en El nervio óptico, y Paloma Vidal en Ensaio de voo. Desde la década del 90, la literatura de César Aira instaló el término "novelitas" para designar esas novelas breves y brevísimas que conmocionaron el sistema de valores en la narrativa argentina contemporánea. Sin el menor indicio de este sentido reconocible del término (al menos para lectorxs argentinxs), el capítulo dedicado a la novela se titula "Las novelitas de las chicas".

11 Sobre la "poética del manuscrito póstumo" en Osvaldo Lamborghini puede verse Strafacce (481, 551). La ansiedad por la inscripción futura en la historia de la literatura argentina puede leerse en Strafacce (454, 483), y en Piglia, (Años de formación 321, Los años felices 156, 342). 
contraseña y abrir ese inédito") (El libro de Tamar 30), y desde la cual lee entonces la fecha del poema con la que titula uno de sus últimos capítulos, " 2 de julio de 2000", sale de los años 70 para ir a cruzarse en cambio con las temporalidades del "Diario Sabático" de Josefina Ludmer, ese primer gran capítulo de Aquí América latina que, publicado recién en 2010, se escribió durante el año 2000, y que, propongo, también converge en esta constelación. El "Diario", que al modo de un archivo incluye una serie de "charlas" sobre el presente (la base de esos pasajes, nos revela Kamenszain en El libro de Tamar, son textos redactados por escritorxs y críticxs amigxs a pedido de Ludmer, en el mismo año 2000, y editados luego al modo de conversaciones y encuentros con la autora), se cierra, justamente, con los "testimonios" de Tamara Kamenszain y Héctor Libertella. En ambos, la "maestra" de la generación del 70 (así la llama en El libro de Tamar) encontrará métodos para practicar una lectura del presente, es decir, del singular "hoy" de "Buenos Aires año 2000", que es su objeto de exploración ${ }^{12}$.

Adelantando las que serán sus hipótesis críticas en La boca del testimonio (2007) y Una intimidad inofensiva (2016), en la "charla" que mantienen en el Jardín Botánico Kamenszain le enseña a Ludmer que lo más revulsivo de la poesía argentina de los jóvenes del 2000 consiste en usar el tiempo pretérito para "traerlo al presente", como un modo de mostrar su inutilidad cuando ya "no hay ningún cuento que contar" y cuando, fuera de toda "literatura", el poema trabaja con lo más cotidiano, con lo más inmediato, con "lo real". ${ }^{13}$ En la transcripción del testimonio, Ludmer se presenta como la teórica que no entiende poesía, o que indaga en la poesía precisamente porque "[l]e sirve para no entender" (105108). Y, sin embargo, es notorio cómo esta lección le servirá enseguida, en el episodio siguiente que cierra el "Diario", y seguramente en el amplio tiempo de la edición, para interpretar nada menos que el testimonio del que para Ludmer es el más "literario" entre lxs escritorxs del 2000: un paseo por las calles de Buenos Aires que Libertella va conduciendo con recurrentes "mirá" y "acordate" (109-113) y que ahora, mientras escribe el "Diario", la afectan como una "pura experiencia del tiempo presente", que finalmente elabora, aunque no lo advierta

12 Ante la nueva experiencia histórica global que es la del "tiempo cero", contexto en el que quiere pensar la transformación de la experiencia del tiempo desde "aquí, América latina" (Ludmer 1719), Josefina Ludmer se propone "explorar" la "temporalidad otra" que percibe en Buenos Aires cuando, en su sabático de la Universidad de Yale, se instala en Argentina durante el año 2000. Se trata de una "experiencia del presente" en la que se yuxtaponen el salto modernizador, la aceleración temporal del neoliberalismo, el presente eterno del Imperio, la laguna temporal del sur, y sobre todo la superposición de una "sensación" de presente como duplicación del pasado con la de utopía y apocalipsis a la vez. A la conjunción de todas estas temporalidades en movimiento, Ludmer la llama "el misterio" o "el secreto del tiempo otro" de "Buenos Aires año 2000" y el "Diario de Sabático" se escribe para "desentrañarlo" (23-35).

13 Las hipótesis son las desarrolladas en el capítulo III de La boca del testimonio, "Testimoniar sin metáfora. (Los casos Washington Cucurto, Martín Gambarotta, Roberta Iannamico)", y las que vuelve a formular sobre los poemas de Iannamico, y en general sobre el uso del presente y del pretérito en la poesía y la narrativa "actuales", en el capítulo I de Una intimidad inofensiva, "Novelas detenidas, poemas que avanzan". 
de este modo, en términos de poesía (de corte y musicalidad), con la lección de Kamenszain: "en algún punto de la ciudad, como en un corte -dice LudmerHL se detiene, pone el pasado en presente y hace música: un acorde aquí-ahoraantes. Y con ese acorde dice presente" (113). En este tempo, que trae el pasado (la superposición de memorias: la urbana, la literaria, la autobiográfica común, la de la amistad) al presente (que es el tiempo en que, le enseñó Kamenszain, "sabe trabajar la poesía”), Ludmer encuentra finalmente la llave para desentrańar el "secreto del tiempo otro" con el que se encontró en el Buenos Aires del 2000.

Lo que Kamenszain, a su vez, aprende con la relectura del "Diario" -que la memoria urbana, de la que fueron testigos la "China" y "Héctor" en su paseo, es una experiencia pública compartida en la que "somos todos contemporáneos"la devuelve, ahora que escribe El libro de Tamar, a la fecha inscripta en el poema, 2 de julio de 2000. La devuelve a esa fecha, apartándola a la vez de la nostalgia que creyó percibir en el fragmento de Libertella cuando lo leyó por primera vez en la edición de 2010 (el malentendido de la nostalgia que, a poco de la muerte de Libertella, pudo traerle el aire de tango de su voz en el paseo), y, sobre todo, distanciándola del tiempo (pasado y futuro) de la consagración que emerge en la convergencia de los relatos próximos de Piglia, Moreno y Strafacce (“¿Será que resblandecimos intentando escribir memorias consagratorias?”, se pregunta), para orientarla en cambio hacia "el veneno contra las mistificaciones" que les "inoculó" Ludmer en su juventud y que, "aun de viejos - dice- [l]os obliga en cada vuelta de tuerca, a instalar[se] de nuevo en lo contemporáneo." En la espiral del tiempo que arman El libro de Tamar, el "Diario sabático" y los textos (intervenidos) de Libertella, Kamenszain atraviesa el presente -ese presente de larga duración que despliega entre el paseo con Ludmer y la hoja de Libertella en 2000, la lectura del "Diario" en 2010, y el momento en que ahora está abriendo las contraseńas del poema-, como un tiempo denso y transparente a la vez, para salir al otro lado de la generación, y a otra forma de comunidad ${ }^{14}$.

Me interesa, para terminar, leer este cruce entre la inscripción del presente y la emergencia de una comunidad, porque es allí donde la experiencia del tiempo se politiza. Un cruce que, creo, se hace ostensible desde La boca del testimonio, cuando Kamenszain articula la "presentificación del presente", como tiempo propio de la poesía, con el testimonio como forma de dar cuenta de la realidad a través de la palabra del otro, y cuando luego lee la política de la poesía de hoy, el testimoniar sin metáfora, como forma de "traer a la vida" lo que está muerto en

14 En su excelente artículo, Adriana Kanzepolsky observa que el nombre de Héctor Libertella se inscribe en forma completa, plenamente, recién en el capítulo "Ramat, 2 de julio de 2000" (un fragmento anterior al que leí aquí, que se titula con la línea entera de la firma del poema, la que incluye lugar y fecha), cuando Kamenszain puede inscribirlo en una trama familiar (vincularlo con el idisch del padre) y en la ciudad judía. Se pregunta entonces si esta fuerte articulación habilitará en El libro de Tamar la posibilidad de "armar nueva trama con materiales viejos" o si, en cambio, será signo de que el paso de prosa de la poeta sigue atrapado en la novela familiar. Mi lectura de " 2 de julio de 2000 " va en otra dirección, hacia la trama que se arma en otro tiempo y en otra comunidad. 
la órbita de una literatura sacralizada. Un cruce que también se hace visible en Una intimidad inofensiva, cuando lee las formas en que "una especie de post-yo", salido de sí y confundiendo sus límites con el mundo, irrumpe en las escrituras de hoy y revitaliza el desgastado yo del formalismo (11). Es decir, un cruce que parece haber cobrado relieve precisamente en los últimos libros en los que, para leer las formas propias de "la escena literaria de hoy", Kamenszain construye un vocabulario crítico donde la inscripción del presente es a la vez una forma de "insuflar vida", y una forma de abrirse al otro, y a lo real ${ }^{15}$.

Es en este sentido que el presente, que en estos últimos ensayos orienta la crítica como una brújula (gran lectora del presente, Kamenszain lee lo que se escribe "hoy", desde "el mundo de hoy" y a partir de lo que está leyendo "hoy", sin necesidad de someterse a la prueba del anacronismo), funciona también ahora con el valor de un "presente vivo" y como una "actualización"16. De ahí el valor de lo performático entre las lecturas de trabajo de Libros chiquitos: la performance under de Batato Barea como nuevo modo de leer la poesía de Alejandra Pizarnik, la lectura en vivo de Cabral de Melo Neto o de Nicanor Parra como forma de socavar la sacralidad de la letra escrita, inclusive el show de las clases de Enrique Pezzoni ante un público ávido, todos estos momentos, en los que "las palabras se vuelven acto" y en los que siempre se crea una forma de comunidad en la escucha (y en la risa), forman parte de la antología, del mismo modo que los $\operatorname{libros}^{17}$. De ahí también el valor de las escenas en las que Kamenszain relata el encuentro con algún escritor (William Burroughs, Enrique Lihn, Juanele Ortiz, Jorge Luis Borges) como una escucha diferida: "creo que me quiso decir...", dice una y otra vez a lo largo del libro. Es la figura del eco, que en El eco de mi madre actualizaba las voces que se escuchan desde lejos y que en la voz de la que narra en El libro de Tamar y Libros chiquitos está siempre atravesada por su resonancia en el presente. La figura podría ser aquí: "ahora que escucho", "ahora que estoy leyendo", "ahora que estoy escribiendo". En la literatura de Kamenszain ese "ahora que” implica siempre una disposición a la escucha, que se abre, a través del encuentro con el otro, a una forma política de comunidad.

15 "Las fechas, en todo este relato íntimo, dejan constancia de que la poesía también tiene edad": con esta frase Kamenszain cierra el prólogo que escribe en abril 2000 para Historias de amor (y otros ensayos sobre poesía) y remite a los efectos que, entiende, produce en su obra la inclusión de El texto silencioso, aquel primer libro de ensayos que cerraba con un "Buenos Aires-México 1976-1981", en esta edición que cerró con un "31 de diciembre de 1999". (Historias de amor 11-12) Me interesa subrayar este prefacio para señalar que la centralidad que siempre tuvieron la "fecha" y la "edad" de la poesía en la literatura de Kamenszain, a partir de La boca del testimonio adopta la forma de una exploración del vínculo radical de la poesía con el presente: con el presente como tiempo del testimonio, pero también como eso que inyecta vida y realidad a la poesía de "hoy".

16 Notablemente, el anacronismo, que a veces parece haberse convertido en un salvoconducto para dejar en claro que no malentendemos "lo contemporáneo" y que estamos a salvo de la superstición de actualidad, no es una categoría a la que necesite recurrir Kamenszain para justificar o fundamentar su interés en leer "lo que se escribe hoy".

17 Las escenas se relatan en los capítulos “¿Se escucha?” y “Yo no sé”. 
En su hermosa lectura de El eco de mi madre y de La novela de la poesía, Florencia Garramuño dice que el dispositivo de apelación e incorporación de otros poemas y otros poetas "crea una red de afectos en los que se sostiene el decir del poema”: una red que, precisa, no es un mero ejercicio de intertextualidad sino una forma de escribir entre voces con la cual la poesía de Kamenszain define "una experiencia de lo común radicalmente hospitalaria", y por eso mismo política (147-151). En el presente que emerge ahora en el tempo de la prosa, El libro de Tamar da aún otra vuelta a ese dispositivo. Precisamente: solo cuando piensa que se está esforzando por entrar en "los secretos que hicieron de ellos una pareja cualquiera”, solo entonces, dice Kamenszain, "[l]e resulta más fácil desclasificar este archivo [el poema] y abrirlo al público" (31). Escrito a cuatro manos -con Julia Kristeva y Phillipe Sollers, con Josefina Ludmer y Ricardo Piglia, con Ted Hughes y Sylvia Plath, las otras parejas con las que va confrontando a lo largo del libro la historia de la suya- El libro de Tamar prepara su cierre con esta constatación: "Dos ecos, entonces, se van alternando para dar testimonio de la historia de una pareja de escritores-lectores" (84). Solo que el testimonio, que para Kamenszain consiste en "recibir en el propio aliento la boca del otro" (La boca del testimonio 12), se fue tramando entre las palabras -los poemas, los mensajes, las notas, las lecturas- de Héctor y Tamara ("por aquí y por allá páginas tuyas mías / escribiéndonos entre nos / pero para otros”, dice el poema que cierra el libro) y es en la confusión que va generando esa alternancia de voces $-\mathrm{y}$ no, aclara, en un gesto autorreferencial sobre la escritura- que El libro de Tamar, como La historia de nuestras vidas que fue su guía, "nunca explica": "solo revela". Por esto, entonces, porque en el mismo acto en que escribe con otros el paso de prosa convierte la historia de amor del matrimonio literario en una historia común (el ghetto de la pareja en comunidad impersonal), la que firma El libro de Tamar "se siente tocada", ahora que escribe este relato, e igual que el que habla en el poema de Mark Strand, por la forma "cruda y desafortunada" de "una historia que tal vez nunca sea contada". A esa forma de testimoniar Kamenszain la llama "poner en fecha lo real", "volver presentes los hechos", y es la forma, dice, que tiene la poesía de aportar una prueba de vida.

\section{Referencias bibliográficas}

Agamben, Giorgio. Idea de la prosa. Buenos Aires, Adriana Hidalgo, 2015.

Cámara, Mario. “¿Cuál es el otro lado del poema?”, https://www.eternacadencia. com.ar/blog/editorial/presentaciones/item/cual-es-el-otro-lado-del-poema. html

Crary, Jonathan. 24/7. El capitalismo tardio y el fin del sueño. Buenos Aires, Paidós, 2015. 
Derrida, Jacques. Mal de archivo. Una impresión freudiana. Madrid, Editorial Trotta, 1997.

Garramuño, Florencia. Mundos en común. Ensayos sobre la inespecificidad en el arte. Buenos Aires, Fondo de Cultura Económica, 2015.

Kamenszain, Tamara. "Los límites del poema-libro". Dispositio, no 1, 1975, 78-81. 2000 .

Historias de amor (y otros ensayos sobre poesía). Buenos Aires, Paidós,

. La boca del testimonio. Lo que dice la poesía. Buenos Aires, Editorial Norma, 2007. 2012.

La novela de la poesía. Poesía reunida. Buenos Aires, Adriana Hidalgo,

. El libro de los divanes. Buenos Aires, Adriana Hidalgo, 2014.

. Una intimidad inofensiva. Los que escriben con lo que hay. Buenos Aires, Eterna Cadencia, 2016.

. El libro de Tamar. Buenos Aires, Eterna Cadencia, 2018.

. Libros chiquitos. Buenos Aires, Ampersand, 2020.

Kanzepolsky, Adriana: “¿'Un paso de prosa'? El libro de Tamar de Tamara Kamenszain”. El jardin de los poetas. Año VI, no 10, primer semestre 2020, 9-23.

Knausgård, Karl Ove. Fin. Mi lucha: 6. Barcelona, Anagrama, 2011.

Laera, Alejandra. "El pase". BazarAmericano, mar.-abr. 2016.

Libertella, Héctor. La arquitectura del fantasma. Una autobiografía. Buenos Aires, Santiago Arcos, 2006.

Ludmer, Josefina. Aqui América latina. Una especulación. Buenos Aires, Eterna Cadencia, 2010.

Lyotard, Jean-Francois. Lo inhumano. Charlas sobre el tiempo. Buenos Aires, Manantial, 1998.

Moreno, María. Black out. Buenos Aires, Penguin Random House, 2016.

. "La musa freudiana". Tamara Kamenszain. El libro de los divanes. Buenos Aires, Adriana Hidalgo, 2015, 7-21.

Piglia, Ricardo. Los diarios de Emilio Renzi. Años de formación. Buenos Aires, Anagrama, 2015. 2016. 2017.

. Los diarios de Emilio Renzi. Años de formación. Buenos Aires, Anagrama, 
Schwarzbök, Silvia. "La pérdida de lo sublime. Consideraciones sobre la estética y el tamaño". En Otra parte, no 15, primavera 2018, pp. 55-59.

Strafacce, Ricardo. Osvaldo Lamborghini. Una biografia. Buenos Aires, Mansalva, 2008. 